\title{
Do Tubular Changes in the Diabetic Kidney Affect the Susceptibility to Acute Kidney Injury?
}

\author{
Volker Vallon \\ Division of Nephrology-Hypertension, Departments of Medicine and Pharmacology, University of California \\ San Diego, and VA San Diego Healthcare System, San Diego, Calif., USA
}

\section{Key Words}

Diabetic nephropathy · Tubular hypothesis - Tubular injury · Regeneration · Clinical studies · Risk factor

\begin{abstract}
Diabetes is the single largest contributor to the growing prevalence of chronic kidney disease (CKD), and episodes of acute kidney injury (AKI) increase the risk of advanced CKD in diabetic patients. Here we discuss whether the pathophysiological changes that occur in the tubular system of the diabetic kidney affect the intrinsic susceptibility to AKI. There is abundant data showing that drug-induced nephrotoxicity is attenuated in rodents with experimental diabetes mellitus, and some mechanistic explanations have been provided, in particular in response to aminoglycosides. Besides downregulation in proximal tubular megalin, which mediates the aminoglycoside uptake in proximal tubules, a role for hyperglycemia-induced activation of regenerative mechanisms has been proposed. The available clinical data, however, indicates that diabetes is a risk factor for AKI, including aminoglycoside nephrotoxicity. While much needs to be learned about this disconnect, the isolated induction of diabetes in otherwise healthy young adult rodents may simply not fully mimic the influence that diabetes exerts in the setting of a critically ill and often elderly patient. We speculate
\end{abstract}

that diabetic tubular growth and the associated molecular signature (including upregulation of TGF- $\beta$, senescence, and inflammation) set up the development of diabetic nephropathy and renal failure in part by increasing the susceptibility to AKI, which further promotes hypoxia and apoptosis. Considering the strong association between AKI episodes and the cumulative risk of developing advanced CKD in diabetes, strategies that reduce $\mathrm{AKI}$ in these patients are expected to help reduce the growing burden of end-stage renal disease.

(c) 2014 S. Karger AG, Basel

\section{The Tubular Hypothesis of Glomerular Filtration and Nephropathy in Diabetes}

Diabetes is the single largest contributor to the growing prevalence of chronic kidney disease (CKD), and 35\% of adults who have diabetes also have CKD [1]. Diabetes mellitus affects the kidney in stages. At the onset, in a subset of diabetic patients the kidneys grow large and the glomerular filtration rate (GFR) becomes supranormal. The tubular hypothesis of glomerular filtration and ne-

Changing Paradigms in Acute Kidney Injury: From Mechanisms to Management - Proceedings of the 5th Annual UAB-UCSD O'Brien Center Symposium (San Diego, Calif., USA, March 4, 2014).

\section{KARGER}

E-Mail karger@karger.com

www.karger.com/nec
C 2014 S. Karger AG, Basel

$1660-2110 / 14 / 1274-0133 \$ 39.50 / 0$
Volker Vallon, MD

Division of Nephrology-Hypertension, Departments of Medicine and Pharmacology University of California San Diego, and VA San Diego Healthcare System 3350 La Jolla Village Drive (9151), San Diego, CA 92161 (USA)

E-Mail vvallon@ucsd.edu 


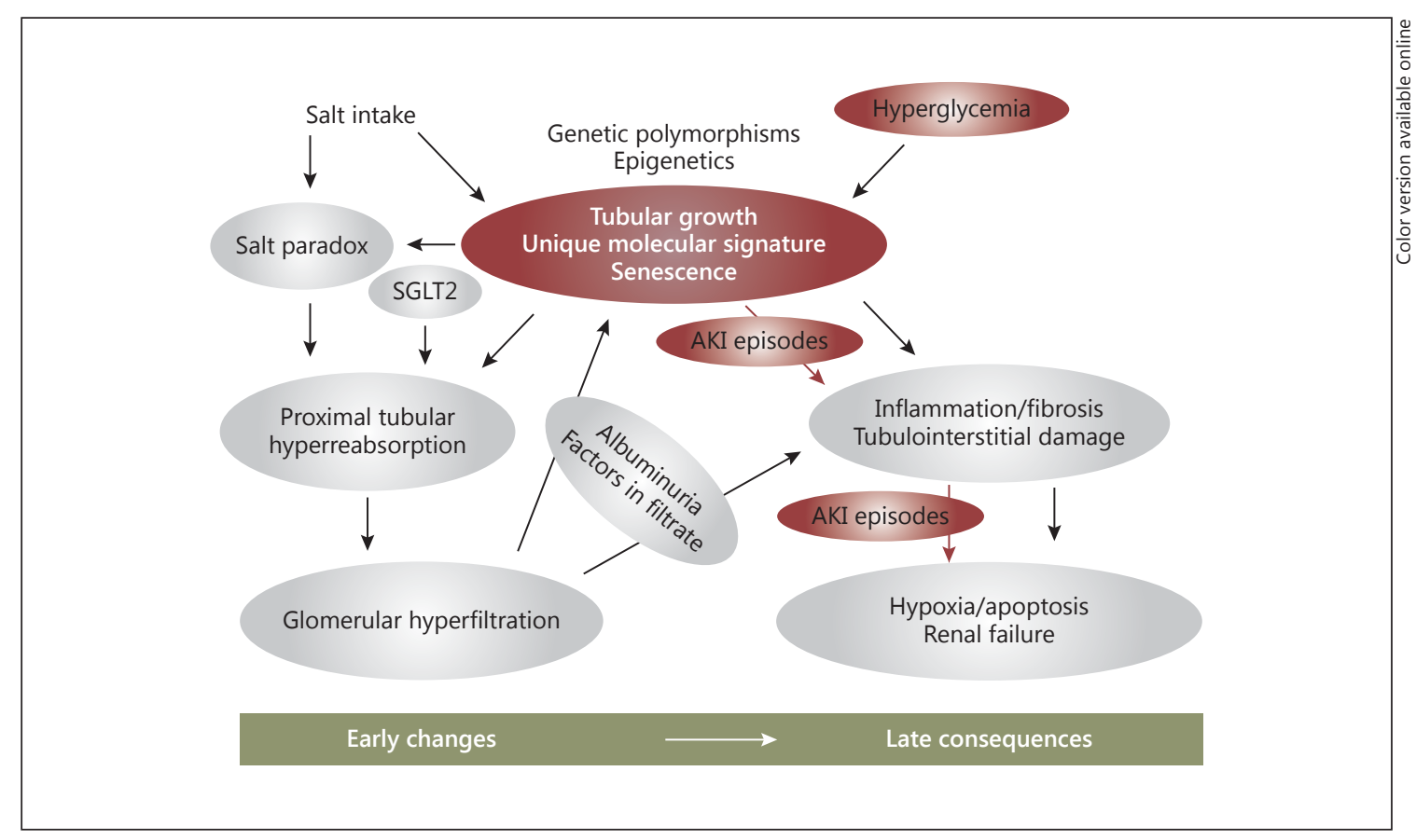

Fig. 1. Tubular hypothesis of glomerular filtration and nephropathy in diabetes mellitus - a proposed role for AKI. The tubular growth response to hyperglycemia differs from patient to patient, in part due to genetic and environmental influences. Diabetic tubular growth and its unique molecular signature determine early functional changes in the diabetic kidney, such as proximal tubular hyperreabsorption, the salt paradox, and glomerular hyperfiltration. The latter promotes inflammation, fibrosis, and tubulointerstitial damage through enhanced glomerular filtration of factors

phropathy in diabetes is a pathophysiological concept to explain these changes that puts the tubular system at the center [2,3] (fig. 1). The concept states that early tubular growth and sodium-glucose cotransport enhance proximal tubular reabsorption and make the GFR supranormal through the physiology of tubuloglomerular feedback (TGF). The diabetic milieu triggers early tubular cell proliferation but the induction of TGF- $\beta$ and cyclin-dependent kinase inhibitors causes $\mathrm{G}_{1}$ cell cycle arrest and switch to tubular hypertrophy and a senescence-like phenotype. While this growth phenotype explains unusual responses like the salt paradox of the early diabetic kidney, the activated molecular pathways may set the stage for tubulointerstitial injury and diabetic nephropathy $[2$, 3]. In other words, we hypothesize that the tubular growth response to hyperglycemia differs from patient to patient and explains early changes in the diabetic kidney, like glomerular hyperfiltration or the salt paradox, but also sets the stage for later diabetic nephropathy and CKD. and proteins (including albumin) that interact with the tubular system. The molecular signature of diabetic tubular growth includes senescence, which releases proinflammatory factors. We hypothesize that both tubular growth/senescence and the induced inflammation, fibrosis, and tubulointerstitial damage enhance the susceptibility of the diabetic kidney to episodes of AKI, which promote the development of late consequences including hypoxia, apoptosis, and renal failure. SGLT2 = Sodium glucose cotransporter 2.

\section{Acute Kidney Injury and the Link to CKD in Diabetes}

Acute kidney injury (AKI) is an established risk factor for CKD. Thakar et al. [4] reported that AKI episodes in diabetic patients are associated with a cumulative risk for developing stage $4 \mathrm{CKD}$; this applied to all levels of baseline renal function and was independent of other major risk factors of progression, and each AKI episode doubled that risk. Drug-induced nephrotoxicity is responsible for $10-20 \%$ of AKI cases [5]. Nephrotoxicity is often the most important limitation for the dosage or intensity of the therapeutic regimen and may lead to serious health complications. Nephrotoxicity is a concern in all clinical settings, but it is of special relevance among critically ill patients, and $\sim 25 \%$ of the 100 most used drugs in intensive care units are potentially nephrotoxic [6]. Factors known to enhance drug nephrotoxicity include excessive dosing, ischemia, and hypovolemia. Here we aim to discuss whether the pathophysiological setting of the diabetic 
kidney affects the intrinsic susceptibility to AKI, with a particular focus on aminoglycoside-induced nephrotoxicity.

\section{Aminoglycoside-Induced AKI Primarily Targets the Proximal Tubule}

Aminoglycosides are widely used for infections by Gram-negative bacteria and bacterial endocarditis. These drugs are not metabolized in the body, have little protein binding $(<10 \%)$, and are freely filtered in the glomeruli. Accumulation of the aminoglycoside gentamicin $24 \mathrm{~h}$ after intraperitoneal injection occurs primarily in lysosomes of the pars recta of proximal tubules via the endocytotic pathway [7]. Aminoglycosides bind to acidic membrane phospholipids, which can alter phospholipid metabolism and may initiate cellular uptake. The megalin-cubilin endocytotic complex, which is localized to the brush border of the proximal tubule, reabsorbs $>95 \%$ of the filtered albumin plus many other ligands (e.g. vitamin D-binding protein) and drugs, including aminoglycosides. Tubular aminoglycoside uptake is inhibited by the megalin antagonist RAP1 [8] and by maleate, which reduces ATP and causes shedding of megalin from the brush border surface, thus impairing receptor-mediated ligand uptake, including aminoglycosides $[9,10]$. Importantly, renal accumulation of aminoglycosides is eliminated in mice lacking megalin [11] (unfortunately, the consequences in AKI have not been tested).

Molitoris and colleagues [12] revealed further details including retrograde trafficking of aminoglycosides through the secretory pathway and cytosolic release via the endoplasmatic reticulum, as well as the importance of subcellular distribution for nephrotoxicity [13]. Using in vivo multiphoton microscopy, the group further showed that the structural and functional changes in the proximal tubules affect first the brush border and lysosomes and subsequently the mitochondria [14]. Aminoglycoside-induced impairment of mitochondrial function reduces ATP generation. As a consequence, aminoglycosides inhibit transport along the nephron and typically induce a nonoliguric or even polyuric clinical manifestation (including proteinuria, enzymuria, aminoaciduria, glycosuria, and electrolyte alterations such as hypercalciuria and hypermagnesuria) [for a review, see 15]. Inhibition of proximal tubular $\mathrm{NaCl}$ reabsorption activates the TGF which, together with tubular obstruction and primary glomerular changes, lowers the GFR. In 1976, Thurau and Boylan [16] coined the term 'acute renal success', implicat-

Do Tubular Changes in the Diabetic

Kidney Affect the Susceptibility to AKI? ing the TGF-mediated GFR reduction in the protection of the body's fluid and electrolyte homeostasis when tubular reabsorption is impaired. TGF resetting has been used as an argument that TGF may not sustain its primary effect on GFR in response to aminoglycosides [15]. However, we know from the pathophysiology of the diabetic kidney that the influence of proximal tubular hyperreabsorption on increases in the GFR (i.e. opposite scenario to AKI) is preserved despite TGF resetting and return of the operating point back to the steeper part of the TGF function [3].

\section{Experimental Diabetes Attenuates the Aminoglycoside Uptake and Nephrotoxicity}

Teixeira et al. [17] reported in 1982 that streptozotocin (STZ) type 1 diabetes in rats prevented the increase in serum creatinine and the decrease in creatinine clearance in response to gentamicin, which was associated with a reduced kidney uptake of the drug and the prevention of tubular necrosis. These findings were subsequently confirmed by multiple groups and shown to be reversed by insulin [18]. It was further shown that STZ diabetes reduces the renal expression of the megalin/cubilin endocytotic complex $[19,20]$ via a mechanism that may include diabetes-induced TGF- $\beta_{1}[21,22]$ and/or matrix metalloproteinase activity, which is elevated in the diabetic kidney and urine [23], and can shed megalin from proximal tubular cell surfaces [24]. Notably, STZ-diabetes-mediated protection in rats or rabbits also includes other nephrotoxins such as cisplatin, mercuric chloride, S-1,2-dichlorovinyl-1-cysteine, and cephaloridine [for references, see 25]. Furthermore, STZ diabetes protects rats from the hepatotoxicity of normally lethal challenges, including thioacetamide, carbon tetrachloride, bromobenzene, and acetaminophen; this hepatoprotection was associated with early onset and robust compensatory hepatic tissue repair which depended on PPAR- $\alpha$ [26]. Similarly, diabetes-induced preplacement of tubular cells in the S-phase of the cell cycle has been proposed to mitigate S-1,2-dichlorovinyl-1-cysteine-initiated AKI by upregulating tissue repair [25]. In other words, hyperglycemia may be a sustained stressor that tonically activates tissue repair ('preconditioning'), which facilitates the initial protective response to a nephrotoxin.

Elliott et al. [27] determined the inulin clearance in STZdiabetic rats in response to gentamicin and confirmed an attenuated initial reduction in GFR associated with a lesser renal drug uptake and necrosis, as well as evidence for regeneration in diabetic kidneys even in the absence of ami- 
Table 1. Diabetes mellitus as a risk factor for the development of AKI

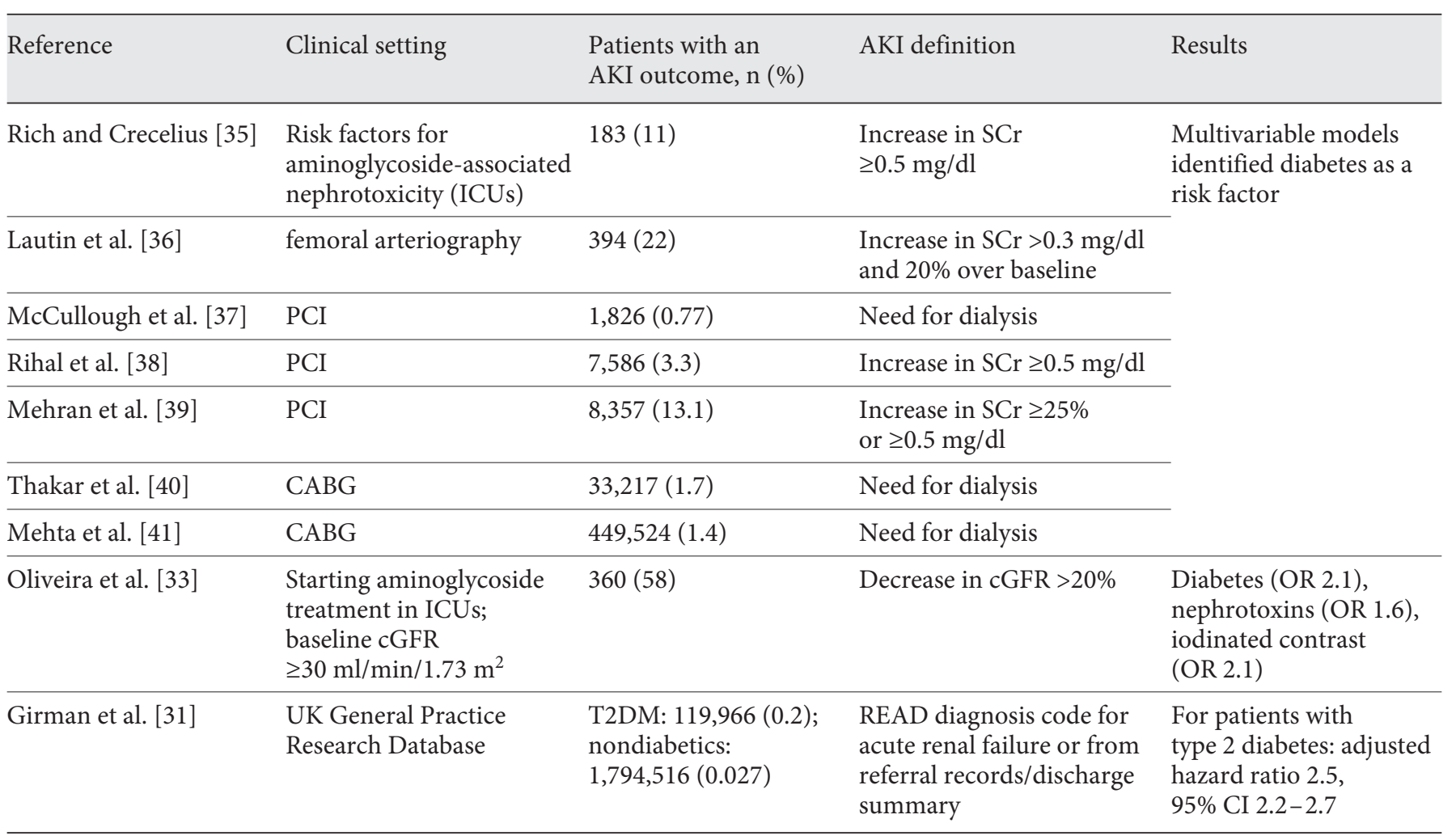

CABG = Coronary artery bypass grafting; $\mathrm{cGFR}=$ calculated GFR; ICU = intensive care unit; OR = odds ratio; $\mathrm{PCI}=$ percutaneous coronary intervention; $\mathrm{SCr}=$ serum creatinine; T2DM = type 2 diabetes mellitus. Based in part on Waikar et al. [42].

noglycosides. In this regard, 4-month-old mice in which the tubular lumen downstream of the early proximal tubule is continuously exposed to enhanced glucose concentrations in the absence of hyperglycemia (due to gene knockout of sodium glucose cotransporter 2) show enhanced renal protein expression of the cyclin-dependent kinase inhibitor p27 and the stress indicator hemoxygenase-1 [28]. Whether these mice show protection against aminoglycoside-induced nephrotoxicity has not been tested.

\section{Do Diabetic Patients Have an Attenuated Renal Aminoglycoside Uptake and Are They Protected from Nephrotoxicity?}

About $70 \%$ of the urinary proteome originates from kidney or genitourinary tissues. Thrailkill et al. [29] analyzed the proteins in 24-hour urine samples of individuals with type 1 diabetes with/without microalbuminuria in order to gain mechanistic insight into proteinuria. They found that microalbuminuria in type 1 diabetes was as- sociated with enhanced urinary excretion of megalin and cubilin as well as enhanced urinary excretion of vitamin D-binding protein, and they proposed that aberrant shedding of megalin and cubilin in diabetes could contribute to albuminuria and to deficiency states of vitamins and hormones [29].

A systematic review and meta-analysis of 31 observational studies indicated that diabetes increased the risk of the development of AKI in critically ill patients by $58 \%$, similar to the increase provoked by the application of a nephrotoxin [30]. In accordance, the UK General Practice Research Database found an adjusted hazard ratio of 2.5 for patients with type 2 diabetes to develop AKI [31]. Waikar et al. [32] reported that diabetes was identified as a risk factor for the development of AKI in 7 out of 18 studies that used multivariable models, including 1 study that focused on aminoglycoside-associated nephrotoxicity in the intensive care unit (table 1). More recently, Oliveira et al. [33] confirmed that diabetes doubled the risk for AKI when aminoglycoside treatment was initiated in the intensive care unit. 
These data indicate some disconnect between experimental studies and patients with diabetes, showing that isolated induction of STZ diabetes in otherwise healthy young adult rodents does not capture the influence that diabetes exerts in the setting of critically ill and often elderly patients. Notably, Elliott et al. [27] also reported that the improvement in inulin clearance observed in nondiabetic rats between days 14 and 21 of gentamicin application was completely absent in STZ-diabetic rats. Moreover, inflammation, oxidative stress, hypoxia, and fibrosis occur in the established diabetic tubulointerstitium $[2,3]$, a setting that may enhance nephrotoxicity. In this regard, Molitoris et al. [34] described that preceding ischemia can increase apical uptake and induces abnormal intracellular compartmentalization of gentamicin in proximal tubules. Furthermore, the molecular signature of diabetic tubular growth includes a TGF- $\beta$-induced $G_{1}$ cell cycle arrest that causes cell hypertrophy and senescence $[2,3]$. Senescence is a tumor suppressor mechanism that prevents cell division in an injured cell that potentially contains an altered genome. However, senescence also alters the cellular phenotype, which has been proposed to be linked to unusual responses in the diabetic kidney like the salt paradox but also to the release of proinflammatory factors and thereby may contribute to the development of diabetic nephropathy $[2,3]$. Further studies are needed to determine whether senescence enhances the susceptibility of the diabetic kidney to AKI.

\section{Conclusions and Perspectives}

Diabetes can attenuate the nephrotoxicity to aminoglycosides and other nephrotoxins in rodents. The involved mechanisms include inhibition of the megalin-mediated aminoglycoside uptake in the proximal tubule by diabetesinduced TGF- $\beta$ and/or matrix metalloproteinase as well as facilitation of cell repair, possibly due to continuous activation of regenerative mechanisms. We need to better understand the molecular triggers and the effectors of these regenerative mechanisms. We also need to further explore the finding of impaired recovery of GFR in diabetic rodents beyond 14 days of aminoglycoside treatment. There is some evidence for downregulation of megalin in diabetic patients with microalbuminuria. However, multivariable models for the development of AKI in humans have identified diabetes as a risk factor also in the setting of aminoglycoside application, indicating that isolated induction of diabetes in otherwise healthy young adult rodents may not capture the influence of diabetes in the set- ting of critically ill and often elderly patients. It remains to be determined whether patients without microalbuminuria are at greater risk than patients with microalbuminuria, assuming that the latter in part indicates a reduced megalin/cubulin function and, therefore, aminoglycoside uptake. Advanced diabetic kidney injury, senescence, ischemia, inflammation, and enhanced oxidative stress in the diabetic kidney are expected to increase nephrotoxicity. Considering the established strong association in diabetes between episodes of AKI and the cumulative risk for developing advanced CKD, we hypothesize that diabetic tubular growth and the associated molecular signature set up the development of diabetic nephropathy and advanced CKD in part by increasing the susceptibility to AKI (fig. 1). In other words, diabetic patients with larger kidneys are expected to show the greatest susceptibility to the development of AKI. Further studies are needed to test this hypothesis. Better strategies are needed to reduce AKI in diabetic patients to help reduce the growing burden of endstage renal disease.

\section{Acknowledgments}

This work was supported by NIH grants R01DK56248 and R01HL94728, the UAB-UCSD O’Brien Center of Acute Kidney Injury (NIH P30 DK079337), and the Department of Veterans Affairs.

\section{Disclosure Statement}

Within the past 12 months, Dr. Vallon has received research grant support for basic science studies from Boehringer Ingelheim Pharma GmbH \& Co. KG and AstraZeneca.

References

1 Collins AJ, Foley RN, Herzog C, Chavers B, Gilbertson D, Ishani A, Kasiske B, Liu J, Mau LW, McBean M, Murray A, St PW, Guo H, Li Q, Li S, Li S, Peng Y, Qiu Y, Roberts T, Skeans M, Snyder J, Solid C, Wang C, Weinhandl E, Zaun D, Arko C, Chen SC, Dalleska F, Daniels F, Dunning S, Ebben J, Frazier E, Hanzlik C, Johnson R, Sheets D, Wang X, Forrest B, Constantini E, Everson S, Eggers P, Agodoa L: United States Renal Data System 2008 Annual Data Report. Am J Kidney Dis 2009;53:S1-S374.

2 Vallon V: The proximal tubule in the pathophysiology of the diabetic kidney. Am J Physiol Regul Integr Comp Physiol 2011; 300:R1009-R1022.

3 Vallon V, Thomson SC: Renal function in diabetic disease models: the tubular system in the pathophysiology of the diabetic kidney. Annu Rev Physiol 2012;74:351-375. 
-4 Thakar CV, Christianson A, Himmelfarb J, Leonard AC: Acute kidney injury episodes and chronic kidney disease risk in diabetes mellitus. Clin J Am Soc Nephrol 2011;6:25672572.

5 Brivet FG, Kleinknecht DJ, Loirat P, Landais PJ: Acute renal failure in intensive care units - causes, outcome, and prognostic factors of hospital mortality: a prospective, multicenter study. French Study Group on Acute Renal Failure. Crit Care Med 1996;24:192-198.

6 Taber SS, Mueller BA: Drug-associated renal dysfunction. Crit Care Clin 2006;22:357-374, viii.

7 Lopez-Novoa JM, Quiros Y, Vicente L, Morales AI, Lopez-Hernandez FJ: New insights into the mechanism of aminoglycoside nephrotoxicity: an integrative point of view. Kidney Int 2011;79:33-45.

8 Moestrup SK, Cui S, Vorum H, Bregengard C, Bjorn SE, Norris K, Gliemann J, Christensen EI: Evidence that epithelial glycoprotein 330/ megalin mediates uptake of polybasic drugs. J Clin Invest 1995;96:1404-1413.

-9 Nagai J, Takano M: Molecular aspects of renal handling of aminoglycosides and strategies for preventing the nephrotoxicity. Drug Metab Pharmacokinet 2004;19:159-170.

10 Nagai J, Tanaka H, Nakanishi N, Murakami $\mathrm{T}$, Takano M: Role of megalin in renal handling of aminoglycosides. Am J Physiol Renal Physiol 2011;281:F337-F344.

11 Schmitz C, Hilpert J, Jacobsen C, Boensch C, Christensen EI, Luft FC, Willnow TE: Megalin deficiency offers protection from renal aminoglycoside accumulation. J Biol Chem 2002;277:618-622.

12 Sandoval RM, Molitoris BA: Gentamicin traffics retrograde through the secretory pathway and is released in the cytosol via the endoplasmic reticulum. Am J Physiol Renal Physiol 2004;286:F617-F624.

13 Sandoval RM, Reilly JP, Running W, Campos SB, Santos JR, Phillips CL, Molitoris BA: A non-nephrotoxic gentamicin congener that retains antimicrobial efficacy. J Am Soc Nephrol 2006;17:2697-2705.

14 Hall AM, Rhodes GJ, Sandoval RM, Corridon PR, Molitoris BA: In vivo multiphoton imaging of mitochondrial structure and function during acute kidney injury. Kidney Int 2013; 83:72-83.

15 Lopez-Novoa JM, Quiros Y, Vicente L, Morales AI, Lopez-Hernandez FJ: New insights into the mechanism of aminoglycoside nephrotoxicity: an integrative point of view. Kidney Int 2011;79:33-45.

16 Thurau K, Boylan JW: Acute renal success: the unexpected logic of oliguria in acute renal failure. Am J Med 1976;61:308-315.

17 Teixeira RB, Kelley J, Alpert H, Pardo V, Vaamonde CA: Complete protection from gentamicin-induced acute renal failure in the diabetes mellitus rat. Kidney Int 1982;21:600612.

18 Gouvea W, Roth D, Alpert H, Kelley J, Pardo $\mathrm{V}$, Vaamonde CA: Insulin reverses the pro- tection given by diabetes against gentamicin nephrotoxicity in the rat. Proc Soc Exp Biol Med 1994;206:445-453.

-19 Tojo A, Onozato ML, Ha H, Kurihara H, Sakai T, Goto A, Fujita T, Endou H: Reduced albumin reabsorption in the proximal tubule of early-stage diabetic rats. Histochem Cell Biol 2001;116:269-276.

20 Yin D, Yin J, Yang Y, Chen S, Gao X: Renoprotection of danshen injection on streptozotocin-induced diabetic rats, associated with tubular function and structure. J Ethnopharmacol 2014;151:667-674.

-21 Gekle M, Knaus P, Nielsen R, Mildenberger S, Freudinger R, Wohlfarth V, Sauvant C, Christensen EI: Transforming growth factor-betal reduces megalin- and cubilin-mediated endocytosis of albumin in proximal-tubule-derived opossum kidney cells. J Physiol 2003; 552:471-481.

22 Russo LM, del RE, Brown D, Lin HY: Evidence for a role of transforming growth factor (TGF)-betal in the induction of postglomerular albuminuria in diabetic nephropathy: amelioration by soluble TGF-beta type II receptor. Diabetes 2007;56:380-388.

23 Thrailkill KM, Clay BR, Fowlkes JL: Matrix metalloproteinases: their potential role in the pathogenesis of diabetic nephropathy. Endocrine 2009;35:1-10.

24 Biemesderfer D: Regulated intramembrane proteolysis of megalin: linking urinary protein and gene regulation in proximal tubule? Kidney Int 2006;69:1717-1721.

25 Dnyanmote AV, Sawant SP, Lock EA, Latendresse JR, Warbritton AA, Mehendale HM: Diabetic mice are protected from normally lethal nephrotoxicity of S-1,2-dichlorovinyl-L-cysteine (DCVC): role of nephrogenic tissue repair. Toxicol Appl Pharmacol 2006;211:133-147.

26 Shankar K, Vaidya VS, Corton JC, Bucci TJ, Liu J, Waalkes MP, Mehendale HM: Activation of PPAR-alpha in streptozotocin-induced diabetes is essential for resistance against acetaminophen toxicity. FASEB J 2003; 17:1748-1750.

27 Elliott WC, Houghton DC, Gilbert DN, Baines-Hunter J, Bennett WM: Experimental gentamicin nephrotoxicity: effect of streptozotocin-induced diabetes. J Pharmacol Exp Ther 1985;233:264-270.

-28 Vallon V, Rose M, Gerasimova M, Satriano J, Platt KA, Koepsell H, Cunard R, Sharma K, Thomson SC, Rieg T: Knockout of Na-glucose transporter SGLT2 attenuates hyperglycemia and glomerular hyperfiltration but not kidney growth or injury in diabetes mellitus. Am J Physiol Renal Physiol 2013;304:F156-F167.

29 Thrailkill KM, Nimmo T, Bunn RC, Cockrell GE, Moreau CS, Mackintosh S, Edmondson RD, Fowlkes JL: Microalbuminuria in type 1 diabetes is associated with enhanced excretion of the endocytic multiligand receptors megalin and cubilin. Diabetes Care 2009;32: 1266-1268.

30 Cartin-Ceba R, Kashiouris M, Plataki M, Kor DJ, Gajic O, Casey ET: Risk factors for devel- opment of acute kidney injury in critically ill patients: a systematic review and meta-analysis of observational studies. Crit Care Res Pract 2012;2012:691013.

31 Girman CJ, Kou TD, Brodovicz K, Alexander CM, O’Neill EA, Engel S, Williams-Herman DE, Katz L: Risk of acute renal failure in patients with type 2 diabetes mellitus. Diabet Med 2012;29:614-621.

32 Waikar SS, Liu KD, Chertow GM: Diagnosis, epidemiology and outcomes of acute kidney injury. Clin J Am Soc Nephrol 2008;3:844-861.

33 Oliveira JF, Silva CA, Barbieri CD, Oliveira GM, Zanetta DM, Burdmann EA: Prevalence and risk factors for aminoglycoside nephrotoxicity in intensive care units. Antimicrob Agents Chemother 2009;53:2887-2891.

- 34 Molitoris BA, Meyer C, Dahl R, Geerdes A Mechanism of ischemia-enhanced aminoglycoside binding and uptake by proximal tubule cells. Am J Physiol 1993;264:F907-F916.

35 Rich MW, Crecelius CA: Incidence, risk factors, and clinical course of acute renal insufficiency after cardiac catheterization in patients 70 years of age or older: a prospective study. Arch Intern Med 1990;150:1237-1242.

36 Lautin EM, Freeman NJ, Schoenfeld AH, Bakal CW, Haramati N, Friedman AC, Lautin JL, Braha S, Kadish EG, Sprayregen S: Radiocontrast-associated renal dysfunction: incidence and risk factors. AJR Am J Roentgenol 1991;157:49-58.

- 37 McCullough PA, Wolyn R, Rocher LL, Levin $\mathrm{RN}$, O'Neill WW: Acute renal failure after coronary intervention: incidence, risk factors, and relationship to mortality. Am J Med 1997; 103:368-375.

- 38 Rihal CS, Textor SC, Grill DE, Berger PB, Ting HH, Best PJ, Singh M, Bell MR, Barsness GW, Mathew V, Garratt KN, Holmes DR Jr: Incidence and prognostic importance of acute renal failure after percutaneous coronary intervention. Circulation 2002;105: 2259-2264.

39 Mehran R, Aymong ED, Nikolsky E, Lasic Z, Iakovou I, Fahy M, Mintz GS, Lansky AJ, Moses JW, Stone GW, Leon MB, Dangas G: A simple risk score for prediction of contrastinduced nephropathy after percutaneous coronary intervention: development and initial validation. J Am Coll Cardiol 2004;44:13931399.

40 Thakar CV, Worley S, Arrigain S, Yared JP, Paganini EP: Influence of renal dysfunction on mortality after cardiac surgery: modifying effect of preoperative renal function. Kidney Int 2005;67:1112-1119.

41 Mehta RH, Grab JD, O’Brien SM, Bridges CR, Gammie JS, Haan CK, Ferguson TB, Peterson ED: Bedside tool for predicting the risk of postoperative dialysis in patients undergoing cardiac surgery. Circulation 2006;114:22082216.

42 Waikar SS, Liu KD, Chertow GM: The incidence and prognostic significance of acute kidney injury. Curr Opin Nephrol Hypertens 2007; 16:227-236. 